that his experience had not led him to Mr. Salmon's conclusions.

Mr. SALMON had never stated, that they were necessarily dependent on each other, or that they were always concomitant. He had often seen cases of diseased rectum without phthisis pulmonalis; and it was not because any gentleman chose to say his experience did not lead him to agree with the conclusion of another, that therefore the doctrine was to be considered by the profession as unsound. He himself had attended a case with Dr. Farr, of ascites, with a diseased rectum as the exciting cause, where he had been requested by the Doctor to tap the patient, never once suspecting a disease of the rectum. Mr. Salmon, however, cured the patient of a stricture of the rectum, the symptoms of ascites subsided, and the patient got perfectly well. He afterwards went to Dr. Farr under a sort of disguise, who prescribed for him as if he had been labouring under an affected liver, without recollecting he had ever seen the man before. On one occasion, Dr. Fart had expressed himself thus :-" I have a great liking to see you succeed in your profession, Mr. Salmon, and I hope you will, bat I trust you will not split on the rock you have been setting up to me. I have never seen a diseased rectum in the course of 40 years' experience." Mr. Salmon enquired if he had ever looked for one? The Doctor replied, "I do not know that I have."

Mr. Brown was sure Dr. Farr had never examined a rectum, unless in some case or cases where he had been required to do so by the surgeon, from the surgeon having had conbt as to the nature of the malady.

Mr. SALMON considered it highly improper for any gentleman, from such very limited personal experience upon this subject, to impugn the doctrine of another, who had made the diseases and examinations of these parts the great portion of his study and occupation. Post-mortem examinations of the rectum had been very much and blame. ably overlooked by the profession.

Wr. SHEARLEY cordially concurred with Mr. Salmon in his last observation. For his own part, he had hardly ever seen a rec. tum examined, and he believed that very few medical men ever thought of examining it.

Mr. Proctor entered the Society at a late hour, and by an observation he made, showed that he had split on the same rock against which Mr. Brown foundered, namely, the assumption that $\mathrm{Mr}$. Salmon had maintained, that disease of the lungs and of the rectum were necessarily associated.

A further dodging sort of discussion took place on the subject, in which the anatomy of the rectum, the physiology of its action, the power the mind has over it, and the sympathy existing between it and other visceræ, were descanted on, but in the course of which no wonderful light struck the Society. Mr. Dermot took so active a part in the debate, as to have required to be informed, both by the fidgetty state of the members' feet, and from the lips of the Chairman, that gentlemen were out of order who spoke more than twice on the same subject in the course of the evening, before all present had had an opportunity of deli. vering their sentiments.

Dr. BLIck wished to correct a statement that had appeared in print, respecting what he had said on the use of the ergot of rye, upon the discussion of Mr. Lord's late case. The person who had made the statement had signed himself R. C., or R. S. What he (Mr. Blick) believed he had really said on this medicine was, that he had given it in many cases where labour had taken place afterwards, but that he did not believe the labour was the result of the ergot, inasmnch as it was not invariably the consequence of it.

\section{DR. HASLAM'S RESIGNATION.}

\section{To the Editor of 'THE Lancet,}

Sir,-Feeling, under existing circumstances, I have no security that the following letter will be divulged to those Gentlemen whom I wish to address; and as I desire my sentiments to have the utmost publicity, I solicit their promulgation through the medium of your inpartial and widely. circulated Journal.

$$
\begin{aligned}
& \text { Your obedient servant, } \\
& \text { Jorn HASLAM. }
\end{aligned}
$$

15th Jan. 1829.

TO THE MEMTERS OF THE MEDICAL BOCIETY OF LON DON.

Gentifmen, - When the wholesome and protecting laws of a comniunity are subverted, in order to facilicate the baneful intrusion of human passions, there is a natural inference, that its existence will be of very limited duration. In your printed book of Statutes, page 9. chap. 4, which treats of the duties of the President, it is expressly laid down,-." He shall summon all extra. ordinary meetings of the Society, and enforce the execution of their Statutes." On this subject, as your President, I have never been consulted, nor has my sanction been given to any such proceeding as is contained in the following notice:- 